\title{
BROOKHGUEN
}

NATIONAL LABORATORY

BNL-100986-2013

\section{Challenges to the 2015 NPT Review Conference}

\author{
Susan F. Burk and Katherine Bachner
}

May 2013

\author{
Nonproliferation \& National Security Department \\ Brookhaven National Laboratory
}

\section{U.S. Department of Energy}

Notice: This manuscript has been authored by employees of Brookhaven Science Associates, LLC under Contract No. DE-AC02-98CH10886 with the U.S. Department of Energy. The publisher by accepting the manuscript for publication acknowledges that the United States Government retains a non-exclusive, paid-up, irrevocable, world-wide license to publish or reproduce the published form of this manuscript, or allow others to do so, for United States Government purposes. 


\section{DISCLAIMER}

This report was prepared as an account of work sponsored by an agency of the United States Government. Neither the United States Government nor any agency thereof, nor any of their employees, nor any of their contractors, subcontractors, or their employees, makes any warranty, express or implied, or assumes any legal liability or responsibility for the accuracy, completeness, or any third party's use or the results of such use of any information, apparatus, product, or process disclosed, or represents that its use would not infringe privately owned rights. Reference herein to any specific commercial product, process, or service by trade name, trademark, manufacturer, or otherwise, does not necessarily constitute or imply its endorsement, recommendation, or favoring by the United States Government or any agency thereof or its contractors or subcontractors. The views and opinions of authors expressed herein do not necessarily state or reflect those of the United States Government or any agency thereof. 


\title{
Challenges to the 2015 NPT Review Conference
}

\author{
Susan F. Burk, Consultant, Brookhaven National Laboratory \\ Katherine Bachner, Brookhaven National Laboratory
}

The views expressed in this paper are the authors' and not necessarily those of DOE/BNL

\begin{abstract}
The 2010 NPT Review Conference (RevCon) was viewed as a success in largest part because it adopted a Final Document that included an unprecedented Action Plan that addressed all three pillars of the NPTnonproliferation, disarmament and the peaceful uses of nuclear energy-as well as a decision on the Middle East that outlined steps to be taken to convene a conference to begin to address calls for a Middle East Weapons of Mass Destruction Free Zone (MEWMDFZ). The 2015 NPT RevCon faces a number of challenges to attain a positive outcome that strengthens the NPT and advances its agenda. These challenges include unresolved issues of Treaty compliance and the role of NPT Parties and the review process in addressing them; the role in NPT diplomacy of the Non-Aligned Movement, now led by Iran, whose membership represents a majority of NPT parties; obstacles to convening the Middle East conference endorsed by the 2010 NPT RevCon; and the pressure the NPT Nuclear Weapon States will face to demonstrate further, tangible progress toward nuclear disarmament. This paper will address several challenges facing the 2015 RevCon, and will offer initial ideas for overcoming these barriers to success.
\end{abstract}

\section{The NPT Review Process: A Brief History}

NPT parties have conducted formal reviews of the Treaty every five years since 1975 to assess how well its provisions are being implemented and to recommend steps to improve implementation. From the beginning, the imbalance between the obligations of Non-nuclear Weapon State (NNWS) Parties and Nuclear Weapons States (NWS) Parties was a key point of contention. States that had foresworn nuclear weapons and other nuclear explosives, and accepted comprehensive IAEA safeguards, had fulfilled their NPT commitments. The NWS, that were not disarming fast enough, or at all, had not fulfilled their commitments. The RevCons became an opportunity for NNWS to put pressure on the NWS to step up their efforts to fulfill their nuclear disarmament commitments.

Universal NPT adherence was viewed as the principal means to achieve the Treaty's central nonproliferation objective. The steady growth of membership in the NPT reinforced the perception that this goal was being fulfilled, exacerbating the perceived imbalance between compliance by NNWS Parties and the NPT NWS. Noncompliance by NNWS with their nonproliferation obligations was not an issue at early NPT RevCons. Selective criticism of non-parties to the Treaty, however, was routine as Parties used the review process to call out states already subject to criticism at the United Nations, i.e., South Africa and Israel. Other non-parties with unsafeguarded nuclear programs, including India, Pakistan, Argentina and Brazil received less scrutiny at NPT meetings owing in part, 
perhaps, to their membership in established groups of developing states including the Nonaligned Movement (NAM) and the Group of 77.

The 1995 NPT Review and Extension Conference represented a turning point for the Treaty and the review process. The high stakes of the extension decision for the international regime provided impetus for successful negotiations on the following package of agreements which, by providing "permanence with accountability," enabled the Parties to extend the NPT indefinitely without a vote:

1. Strengthening the Review Process that mandated RevCons every five years, provided for subsidiary bodies to the traditional Main Committee structure to allow for focused discussion of specific issues, and established the process of looking forward as well as back.

2. Principles and Objectives for Nonproliferation and Disarmament that, among other things, recognized the intrinsic relationship between nuclear nonproliferation and nuclear disarmament, and the direct relationship between international security and stability and nuclear disarmament; and

3. A resolution on the Middle East endorsing the establishment of a Middle East zone free of nuclear and other weapons of mass destruction.

Since 1995, the NPT RevCon process has been influenced by the agreement on how to strengthen it, i.e., to enhance its impact on Treaty implementation, and by the principles and objectives. The resolution on the Middle East, however, has continued to eclipse other regional proliferation issues as Arab states, in particular, have worked to use the NPT review process to pressure Israel to join the NPT and accept comprehensive IAEA safeguards. Regrettably, criticism of Israel was not matched by comparable expressions of concern over noncompliance by NPT parties, including Iraq, Libya, Iran and Syria.

The 2000 RevCon produced a substantive Final Document that was a testament to the skill and experience of those who negotiated it. The adoption of 13 practical disarmament steps represented an important achievement, as did the Parties' strong endorsement of the IAEA's Additional Safeguards Protocol. For the first time, all non-parties -- Cuba, India, Israel and Pakistan - were identified by name in an NPT Final Document. The Parties criticized India and Pakistan's 1998 nuclear tests and asserted that neither had the status of a Nuclear Weapon State. But the importance of using the NPT review process to address noncompliance by NPT NNWS continued to be tough to sell. Iraq successfully rebuffed efforts to address allegations of its noncompliance in 2000 using the long-standing consensus rule to block all but the most innocuous language in the Final Document. As the DPRK was absent, the Parties agreed on language regarding its alleged noncompliance. Iran had not yet become an NPT issue (although it was revealed subsequently that it had unsafeguarded nuclear activities even at that time).

The 2005 RevCon failed to build on 2000, foundering early on with disagreements over the conference agenda and allocation of topics among the Main Committees and subsidiary bodies. Procedural wrangling delayed the start of any substantive debate until the RevCon was half over, making it impossible to 
produce any meaningful outcome. Finger-pointing continues to this day over responsibility for the collapse of the 2005 NPT RevCon, but the lesson of 2005 is clear: the sheer number of Treaty Parties, breadth of NPT-relevant issues and political agendas have dramatically increased the difficulty of reaching any kind of agreement by consensus. Preventing progress and blocking agreement is not difficult; finding common ground requires great effort.

Motivated by a strong desire to reinvigorate the NPT by avoiding a repeat of 2005, and buoyed by President Obama's speech in Prague outlining the United States' agenda for reducing nuclear dangers, NPT Parties arrived at the 2010 RevCon with greater willingness to reach across the aisle, forge new partnerships, and search for common ground. The United States was in a strong position. It embraced multilateralism, demonstrated meaningful transparency, and committed publicly, and at the highest level, to the disarmament objective of the NPT, and to strengthening the global nonproliferation regime.

Defying the skeptics and the cynics, the 2010 NPT Review Conference reached agreement on a forward-looking Action Plan, a comprehensive roadmap of measures to advance the NPT's nonproliferation, disarmament and peaceful uses objectives. It also agreed on steps to advance the goal of a Middle East Weapons of Mass Destruction Free Zone (MEWMDFZ).

\section{Toward 2015: Preparations to Date}

Formal preparations for the 2015 NPT Revcon are well underway. The NPT Preparatory Committee (PrepCom) has held sessions in 2012 and 2013 which have focused heavily on implementation of the 2010 Action Plan. No efforts were made to use procedural decisions as an opportunity to delay or obstruct. The Parties got to work quickly. National and group statements demonstrate broad commitment to the 2010 agreements, and to implementation of the Action Plan. Statements also identified priorities for moving forward. Notably, the PrepCom debates reveal that noncompliance by NPT NNWS remains primarily a Western concern, NAM states have joined the West expressing concern about the DPRK's provocative actions. At the same time, developing countries remain principally focused on NWS compliance with their disarmament commitments, and on keeping and even intensifying increasing the pressure on those states to move more rapidly to eliminate their nuclear arsenals.

Although a threatened Arab League boycott of PrepCom II to protest the failure to convene the 2012 Middle East conference did not materialize, on April 29, Egypt'sdelegation head announced Egypt was withdrawing from of the PrepCom protesting "the unacceptable and continuous failure to implement the 1995 Middle East Resolution.", (A spokesman for the Egyptian Presidency put out a statement on May 1 to clarify that Egypt had not withdrawn from the NPT and remained committed to its obligations.)

\section{Challenges Ahead}


Preparations so far for the 2015 NPT RevCon indicate that the Action Plan will be the framework for debate and the point of departure for discussion of next steps to strengthen the Treaty. Meaningful agreement on ways to advance the NPT agenda will not found without fresh thinking and acceptance of the proliferation dilemmas of the $21^{\text {st }}$ century. How the 2015 RevCon grapples with a number of issues may well determine its outcome. These include:

1. Urgent, unresolved issues of Treaty compliance and the role of NPT Parties and the review process in addressing them;

2. The role in NPT diplomacy of the Non-Aligned Movement (NAM), whose membership represents a majority of NPT parties and will be led by Iran through the next RevCon;

3. Resolving the difficult issues that have prevented convening the Middle East conference endorsed by the 2010 NPT RevCon; and

4. Responding to growing pressure on the NPT NWS to demonstrate further, concrete progress toward nuclear disarmament.

\section{Noncompliance and the NPT RevCon Process}

Noncompliance by NPT NNWS has been seen as a narrow preoccupation of the United States and its friends and allies during NPT reviews. Pressures within the NAM for solidarity at NPT meetings has constrained discussion of the ramifications of noncompliance for the Treaty regime, and blocked politically valuable consensus statements reflecting NPT Parties' concern over the threat of NNWS noncompliance on NPT integrity. Developing countries generally have argued that because concerns about NNWS compliance are addressed at the IAEA or the UN, there is no need to deal with them at NPT RevCons. On the other hand, compliance by the NWS with their nuclear disarmament obligations, as noted above, is viewed as key to the Treaty's effectiveness, and thus fair game at RevCons.

Any noncompliance undermines the integrity of the regime, but today states increasingly feel threatened when their NNWS neighbors pursue nuclear activities outside of the IAEA safeguards system or for which there appears no real justification, e.g., Iran's production of enriched uranium to fuel reactors that do not exist, or Syria's clandestine construction of a reactor that could produce weapon-grade plutonium. Acknowledging such concerns in a meeting of Treaty Parties is not a matter of "picking on member states." Rather, the Parties would signal a maturing of the NPT review process that would strengthen the Treaty if they held all Parties accountable for meeting their commitments. Newsweek columnist, Jonathan Alter commenting about the 2010 NPT RevCon wrote, "The treaty is the best way to hold the high ground with Iran and North Korea. Leverage doesn't come from bombast; it comes from the world saying to rogue states, 'We did our part, now you do yours.", ii Simply put, if the NPT parties are unable to show strong and widespread concern about violations of partners of NPT safeguards agreements when they meet to review how well the Treaty is working, how can they expect to maintain an effective NPT regime that works well as a whole; that promotes international and regional peace and security; and that commands respect by all states? 
Pairing a consensus document with a factual report of the RevCon's deliberations reflecting the variety of views that exist on various issueswould ensure that all issues and national positions, and areas of agreement and disagreement were recorded,. Getting consensus agreement, the default for RevCon decision-making at an NPT RevCon, on a strong statement of concern about a specific compliance case is unlikely. The 2010 RevCon President's report and the reports of the Chairmen to the first and second Prepcom for 2015 offer precedents for such a factual, historical record.

Proposals to discourage abuse of the NPT's withdrawal provision by Treaty violators are appropriate topics for RevCon consideration and agreement on broad principles should be pursued. . The NPT Parties can use the review process to signal strong support for full compliance by all Treaty members and to agree on steps they are prepared to take individually and collectively in the event another Party announced its intention to withdraw from the NPT in order to pursue activities prohibited by the Treaty. Strong resistance by a few states, including Iran, must be overcome to secure agreement on key principles and actions to be taken by the Parties if a state exercises its right to withdraw from the Treaty.

NPT Parties also should be prepared to consider introducing a working paper or other statement with as many co-sponsors as possible, to address a specific case of NPT noncompliance. Such an action avoids the divisiveness of voting but could send a powerful political signal that all NPT Parties will be held accountable for compliance.

\section{The role of the NAM}

The Nonaligned Movement (NAM) was established during the Cold War to signal its independence from the two major blocs - NATO and the Warsaw Pact. The Cold War is over and the East and West caucus almost as often together as they do separately. The NAM, however, continues to serve as a coordinating point for the 120 developing countries that are members. Of these, 117 states are party to the NPT giving the NAM bloc considerable clout in NPT meetings. Nuclear disarmament traditionally has been more important to the NAM than nonproliferation ${ }^{\text {iii }}$ and as the only Treaty providing for nuclear disarmament, the NPT and its review process has proven an important venue for the NAM to promote that agenda.

The Prague agenda and the Obama Administration's commitment to multilateral diplomacy were welcomed by the international community, including members of the NAM. Extensive engagement with NAM diplomats during preparations for the 2010 RevCon led to constructive discussions on a wide range of NPT issues, and to a collective, and ultimately successful effort to find common ground, i.e., the Action Plan. In 2010, Egypt held the Presidency of the NAM, and its skillful diplomats encouraged moderation and realism at the RevCon that was critical to its success. Iran is the current president of the NAM and will be through 2015. 
There are already some indications of an uptick in NAM criticism of Western policies $^{\text {iv }}$.

\section{Open the lines of communication and sustained, substantive engagement with NAM partners, both bilaterally and in multilateral settings, will be more important than ever. Frank conversations focusing on priorities,} concerns, and expectations are invaluable, and should become routine. The NPT has never been a zero-sum game and agreement on all issues is neither realistic nor should it be the measure of a successful RevCon. Rather, real success will be measured by the progress the Parties have made to follow up on their 2010 commitments, and by their further collaboration on steps to realize the NPT's objectives.

\section{Middle East}

Intensive negotiations in the run-up to and during the 2010 Revcon produced long-sought agreement on a process leading to a conference in 2012 on a Middle East zone free of weapons of mass destruction (MEWMDFZ), a key element of the 1995 Resolution on the Middle East. This agreement was flawed by its gratuitous focus on Israel's non-NPT status, while Iran, an NPT violator, escaped any mention in the RevCon report. The conference presented a chicken and egg dilemma from the start: should the conference be convened before the agenda was agreed (the Arab view) or should an agenda be established and the conference held thereafter (the U.S. view)? Should progress toward regional peace and security (and recognition of all states' right to exist) be a precondition of any negotiation on a WMDFZ (U.S. view), or should negotiations on a zone be undertaken with the hope that "if they build it, peace will come" (the Arab view).

Notwithstanding the decision's deficits, the U.S. and its partners identified a strong and effective facilitator to prepare the ground for a conference with the hope that his consultations with regional states would resolve these issues.

The Arab Spring interrupted serious discussions and complicated regional governments' ability to overcome these fundamental disagreements. Arab reluctance to engage directly with Israel, or to acknowledge the importance of resolving regional compliance issues, discouraged states from participating, and the conference was postponed indefinitely. The U.S. position has been clear from the start: A conference on a MEWMDFZ must address regional security and stability, and verification and compliance, as well as all WMD. A MEWMDFZ is not something that can be imposed from outside the region, or without the full support of states in the region. And progress on such a zone will occur only if discussed outside the NPT review process.

As noted above, Egypt announced early in its second week that it was withdrawing from the second PrepCom. Notably, no states followed Egypt's lead, and there were reports that none of the Arab states had prior knowledge of Egypt's plans to walk out and were critical of Egyptian unilateralism. ${ }^{\mathrm{v}}$ If true, the Arab Group may not be of one mind on with respect to the conference. There 
may be an opportunity to lower the temperature, regroup and pursue a realistic terms of reference for a conference.

\section{In 2015, NPT Parties should be prepared to seek accountability not only} from the Facilitator, Conveners and the UN, but from the regional states that supported the 2010 decision on the Middle East. Continued, strong U.S. leadership remains essential but will not be sufficient. Ultimately, as stated by the head of the United States delegation to the second PrepCom, regional states bear responsibility for "the big idea - creating the political and security conditions that would make a WMD free zone an achievable concept." vi

\section{Nuclear Disarmament - Defending a Step-by-Step Approach}

The most intense debates at NPT RevCons have been about the size of the NWS nuclear arsenals and the pace of progress to reduce and eliminate them. The 2010 RevCon was no exception. There, however, the debate reflected the very positive international reception of President Obama's speech in Prague with its commitment to seek ratification of the Comprehensive Nuclear Test Ban Treaty (CTBT) and negotiations on a verifiable Fissile Material Cutoff Treaty (FMCT), the successful conclusion of the New START agreement with the Russian Federation and, to a lesser extent, the new U.S. Nuclear Posture Review which reflected a reduced role for nuclear weapons in U.S. security strategy, as well as an updated, i.e., unqualified, Negative Security Assurance (NSA) policy for NPT parties in compliance with their nonproliferation obligations. The principles of transparency, irreversibility and verifiability had been widely accepted by NWS and NNWS alike as essential to further disarmament efforts. The five NPT NWS, the P5, agreed to engage on a series of topics aimed at reducing nuclear dangers, and paving the way for multilateral nuclear disarmament. Although proposals for setting deadlines for disarmament and a Nuclear Weapons Convention were tabled, they did not attract consensus. Nevertheless, the disarmament portion of the Action Plan outlined an ambitious agenda for action by both NWS and NNWS, alike.

Heading into 2015, anticipation about the prospects for progress after Prague have been replaced with frustration. The FMCT talks in Geneva have been held hostage by Pakistan, a non-NPT Party, although the recent decision to commence a Group of Government Experts to explore FMCT-related issues indicates modest progress on that front. The United States continues to lay the groundwork for successful ratification of the CTBT, an achievable goal if facts are put ahead of politics. The U.S. and Russia are discussing next steps after New START but Russian interest in moving immediately to P5 negotiations would appear to delay near-term bilateral progress which the U.S. sees as the essential next step.

Impatience with the pace of the step-by-step disarmament process is setting in. The legitimacy of nuclear deterrence as a security strategy is being increasingly challenged by NNWS. In Oslo in March of this year, the Norwegians followed through on plans announced at the 2012 NPT PrepCom to host a conference on humanitarian consequences of nuclear weapons use, and Mexico has agreed to 
host a follow-on event. At the 2013 PrepCom South African tabled a paper with 78 co-sponsors, including several NATO allies, urging that the catastrophic humanitarian consequences of any use of nuclear weapons inform the work of the NPT review cycle. Support for setting deadlines for the elimination of nuclear weapons and moving directly to negotiations on a Nuclear Weapons Convention continues to grow, both among NAM members and the nongovernmental community. While the language of these initiatives does not distinguish between NPT parties and non-parties possessing nuclear weapons, only the P5 are held accountable in the NPT review process. Taken together, these developments distract from actual disarmament accomplishments, divert attention from realistic and achievable measures, and, in the long run, may devalue the step-by-step process which is politically and practically the only course available under current circumstances. By focusing exclusively on the P5, moreover, these efforts shift the focus away from the corrosive effect on the regime of noncompliance from within, diminish the responsibility of NNWS for upholding the nonproliferation norm, and could polarize efforts to strengthen the NPT broadly. It also fails to recognize that states outside the NPT with known nuclear arsenals will need to be part of the disarmament process at some point.

While the United States nuclear agenda is ambitious and far-reaching, major breakthroughs are not assured by 2015. Nevertheless, there are opportunities for the NWS to demonstrate progress on Action Plan measures that reflect fidelity to the 2010 agreements. The U.S. already has set a high bar for transparency among the P5, and can explore how to build on its performance in the run-up to 2015.

Technical discussions of the verification challenges raised by an FMCT and/or very low numbers of nuclear weapons that brought together NWS, NNWS and NGOs would build confidence and could translate to more informed debate on nuclear disarmament in 2015. This also might have the added benefit of validating the merits of the step-by-step approach to disarmament.

The 2010 Nuclear Posture Review can be better explained to NPT partners both to correct misunderstandings (or misrepresentations) about its conclusions, and to highlight its transformative elements, e.g., the NSA policy.

Finally, it is time to begin a serious discussion of the implications for the disarmament agenda of regional and international insecurity and instability, as well as the responsibility NNWS have for contributing to the nonproliferation conditions that will make disarmament possible. Dr. Scott Sagan, CISAC ${ }^{\text {vii }}$ and Dr. James Acton, Carnegie ${ }^{\text {viii }}$ have made valuable contributions on this issue that need to find their way into NPT discussions.

\section{Conclusion}

One of the more difficult challenges facing 2015 may be a psychological one: With one exception (1995 and 2000), every RevCon declared a success (i.e., producing agreement on a Final Document or other decisions) has been followed by a RevCon deemed unsuccessful due to its failure to agree on a substantive 
report. Much has been made of the importance of the mood or "vibe" of a RevCon, and many participants in 2010 agree that the positive mood of delegations going into the 2010 RevCon was important to the outcome. The 2010 RevCon also got a lift from the perceived need to avoid a repeat of the 2005 Revcon which together with the multiple challenges to the NPT regime (e.g., Iran, DPRK, AQ Khan) led some observers to declare the NPT past its "sell by" date. A careful review of the PrepCom debate so far leads us to conclude that the challenges discussed above are significant but surmountable. We believe the Parties have the tools to consolidate the achievements of 2010 when they meet to review the NPT in 2015.

\footnotetext{
${ }^{\mathrm{i}}$ Statement by Ambassador Hisham Badr, Assistant Minister of Foreign Affair for International Organizations and Multilateral Affairs of the Arab Republic of Egypt before the Second Session of the Preparatory Committee to the 2015 NPT Review Conference, Geneva, April 29, 2013

ii Alter, Jonathan, "Bring in the Big Guns, Obama Prioritizes Nonproliferation," Newsweek, April 19, 2010.

iii Potter, William and Gaukhar Mukhatzhanova, "Nuclear Politics and the Non-Aligned Movement," The International Institute for Strategic Studies, February 2012

iv Comparison of the NAM Working Papers on peaceful uses from the 2012 and 2013 PrepComs reveals sharper criticism of controls on sensitive technology in the 2013 paper than the NAM's 2012 PrepCom paper on the same subject. In the former, the NAM "rejects, in principle, any attempt aimed at discouraging certain peaceful nuclear activities on the grounds of their alleged 'sensitivity." In the 2012 NAM statement, the group "emphasizes that the Treaty does not prohibit the transfer or use of nuclear technology, equipment or material for peaceful purposes based on their sensitivity...."

"Grossman, Elaine M. "Egypt States Walkout Over Failure to Convene Mideast WMD Summit," Global Security Newswire, April 30, 2013

${ }^{v i}$ Statement by Assistant Secretary of State Thomas Countryman, Second Session of the NPT Preparatory Committee, Geneva, April 29, 2013.

vii Sagan, Scott D., "Shared Responsibilities for Nuclear Disarmament," Daedulus, Spring 2009

viii Acton, James M. "Bombs Away? Being Realistic about Deep Nuclear Reductions," The

Washington Quarterly, Spring 2012
} 